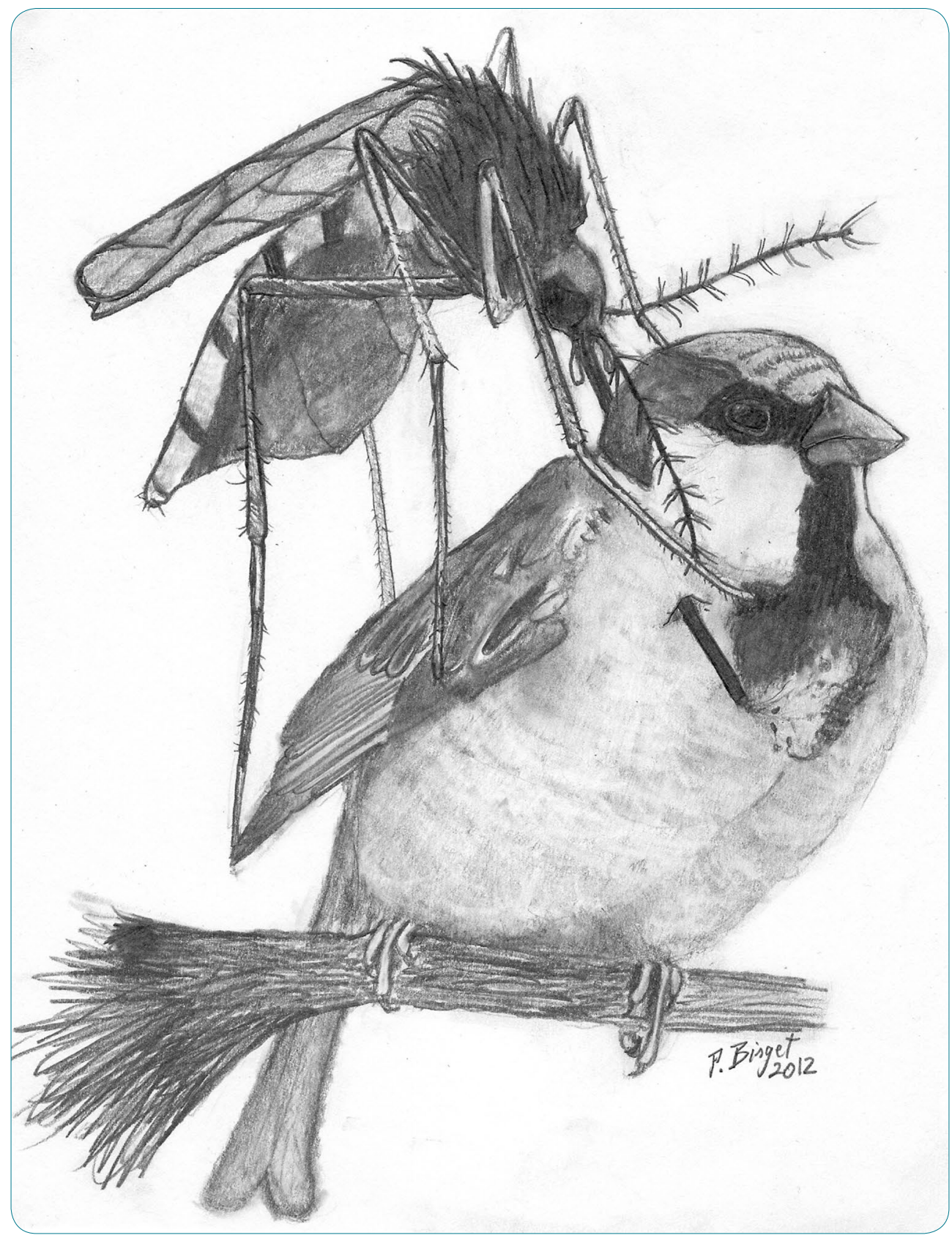

\title{
Maternal effects, malaria infections and the badge size of the house sparrow
}

Birget and Larcombe 


\title{
Maternal effects, malaria infections and the badge size of the house sparrow
}

\author{
Philip L. G. Birget ${ }^{1,2^{*}+}$ and Stephen D. Larcombe $3,4,5,6+$
}

\begin{abstract}
Background: The evolution of sexual signals is not only determined by immediate sexual selection but also by selection arising from the environment and the interaction with developmental effects. In this study we aimed to investigate how the badge size of male house sparrows (Passer domesticus) is correlated to avian malaria infections as well as to prenatal testosterone exposure, measured as the 2D:4D digit ratio. The rationale behind this study is that the immunosuppressive effect of maternal testosterone deposition combined with the fitness cost imposed by parasites may cause important trade-offs to the development of secondary sexual signals.

Methods: Assuming that vector abundance is a key variable associated with infection risk by avian malaria, we caught adult male sparrows from eight different populations in the Camargue, France, four of which were located in a vector-controlled area, and the other four in an untreated area. For each bird we measured its badge size, digit ratio and took blood to determine its infections status. We used PCR to identify the malaria parasite species and strain that caused the infection.
\end{abstract}

Results: Contrary to our expectation, prevalence of disease did not differ across the vector-treatment regions, with around $80 \%$ of birds being infected in both areas, and those infections were caused largely by a single strain, Plasmodium relictum SGS1. Although infected birds had a badge size not significantly different from uninfected males, there was a condition-dependent association between badge size, infection status and maternal testosterone deposition.

Conclusions: This study illustrates that the complexity of temporal and ecological dimensions makes the relationships between disease, testosterone-related traits and secondary sexual signals that have been previously reported less general than thought.

Keywords: Avian malaria, Digit ratio, Passer domesticus, Sexual signals

\section{Background}

The optimal allocation of limited resources is a fundamental selection pressure faced by any individual (Stearns 1992). Diseases pose a particular problem to an organism, since trade-offs can occur at two levels: (1) the parasite uses up host energy for its own growth and transmission and (2) the host invests energy to fight the parasite with costly immune responses (Hamilton and Zuk 1982; Sheldon and Verhulst 1996). Hamilton and Zuk first highlighted the potential importance of

\footnotetext{
*Correspondence: philipbirget@gmail.com

${ }^{\dagger}$ P. L. G. Birget and S. D. Larcombe contributed equally to this work.

'St Peter's College, University of Oxford, New Inn Hall Street, Oxford OX1

2DL, UK

Full list of author information is available at the end of the article
}

parasites in maintaining genetic variation involved in sexual selection, mediated by trade-offs affecting the development of costly secondary sexual signals (Hamilton and Zuk 1982). It is the costliness of male secondary sexual signals that offers the basis for female choice (Zahavi 1975). Foldstad and Karter's (1992) immunocompetence hypothesis $(\mathrm{ICH})$ proposed a proximate mechanism for a trade-off between elaboration of sexual signals and disease susceptibility involving testosterone. This hormone is involved in the development of many secondary sexual signals (Andersson 1994) and also has a well-documented immunosuppressive effect (Saino et al. 1995; Verhulst et al. 1999; Duffy et al. 2000), which may lead to a situation where individuals cannot qualitatively increase their sexual ornamentation without increasing 
their susceptibility to disease. Hence, only individuals with an inherent "quality" such as an ability to acquire large energy reserves, or possession of parasite-resistance genes, can afford higher testosterone production. However the importance of these hypotheses in natural populations remains controversial as many studies fail to consider the intricate natural context in which sexual signals evolve. Sexual signals are influenced by natural selection, early development, as well as phenotypic plasticity; all of which are known to vary widely across environments (Cornwallis and Uller 2010). Varying parasite abundance constitutes a particularly important mediator of environmental heterogeneity and hence may differentially affect the evolutionary ecology of sexual signals in hosts. The early developmental environment deserves special consideration in the development of sexual signals due to its susceptibility to parental effects-a theory now widely accepted by evolutionary biologists (Danchin et al. 2011). "Parental effects" can be defined as any process mediated by the parent(s) that has an impact on the developing phenotype of the offspring. In order to gain a more complete picture of the evolutionary context of secondary sexual traits, parental effects should be considered as they may have important impacts on the ontogeny and evolution of these traits (Badyaev et al. 2009). One important parental effect in birds is the amount of testosterone deposited into the egg by the female (Schwabl 1993). Embryonic development in eggs with variable testosterone concentration has been shown to predict such important phenotypic traits as begging behaviour (Müller et al. 2007), posthatching growth (Schwabl 1996), immunocompetence (Groothuis et al. 2005; Tschirren 2005; Sandell et al. 2009), aggression (Partecke and Schwabl 2008), and secondary sexual signals (Galván and Alonso-Alvarez 2010). Many immunological and ecological studies show that testosterone has a distinct immunosuppressive effect (Zuk 1996; Roberts et al. 2004). A well-established correlate of embryonic and foetal testosterone exposure across many vertebrates is the 2D:4D digit ratio (Manning 2002). In birds, high androgen deposition results in elevated digit ratios which have been shown to correlate with morphological, physiological and behavioural traits (Burley and Foster 2004; Navarro et al. 2007; Cain et al. 2013). The House Sparrow (Passer domesticus) is a promising model species for investigating secondary sexual signals in their evolutionary context for several reasons: it has a well-studied sexual signal (the male badge), it occurs along different environmental matrices, it has low rates and distances of dispersal (Anderson 2006) and offers scope for studying adaptation to local selection pressures (Loiseau et al. 2009). The highly variable badge size of male house sparrows has been the target of a number of investigations over the last three decades, e.g., (Møller 1987; Griffith et al. 1999; Laucht and Dale 2012), though the function and condition-dependence of this melaninbased signal remain controversial: One meta-analysis (Nakagawa et al. 2007) confirmed its importance in social signaling to establish hierarchies, as reported by a number of studies Møller (1987); Poiani et al. 2000; Buchanan et al. 2010), but found weak evidence that it is actually a sexually-selected signal. Although the ability to mount an immune response has been linked to badge size on several occasions (Navarro et al. 2004; Buchanan et al. 2003), remarkably few studies have established correlations between badge size and parasite load. Indeed there are two mechanisms by which parasites could influence badge size in natural populations: (1) direct physiological trade-offs, or (2) alteration of dominance hierarchies, which has been shown to impact badge size at the following moult (Dolnik et al. 2010).

In this study, avian malaria was our disease of choice as it is one of the most prevalent and best investigated avian vector-transmitted diseases. Avian malaria infections can be caused by by three genuses of apicomplexans: Haemoproteus, Plasmodium and Leucocytozoon which are transmitted by hippoboscid flies, Culex-mosquitoes and blackflies respectively. The considerable heterogeneity in transmission of vector-transmitted diseases across time and space in conjunction with the high prevalence in affected bird populations across the world make these infections a major source of divergent selection pressures to host populations that drive genetic evolution (Bonneaud et al. 2006; Randolph and Rogers 2010; Marzal et al. 2011). To explore the effect of malaria and developmental testosterone exposure on badge size we needed sufficient sample sizes of birds that differ in their infection status but should otherwise experience a similar environment. The Camargue, a region in the Rhône delta of southern France known for its high mosquito prevalence during the summer months (Ponçon et al. 2007) provides an ideal environment for investigating such effects because some areas have been subjected to mosquito control for several decades, whereas other areas have been protected from these control programs (Poulin 2012). We reasoned that since regular large-scale insecticide treatment alters vector densities (Ponçon et al. 2007), this should be reflected in the avian malaria prevalence of house sparrows. We attempted to use this environmental difference to set the male badge into its ecological context, and address the links between risk of malaria infection, male badge size, and foetal testosterone-exposure (see Fig. 1 for a schematic representation). 


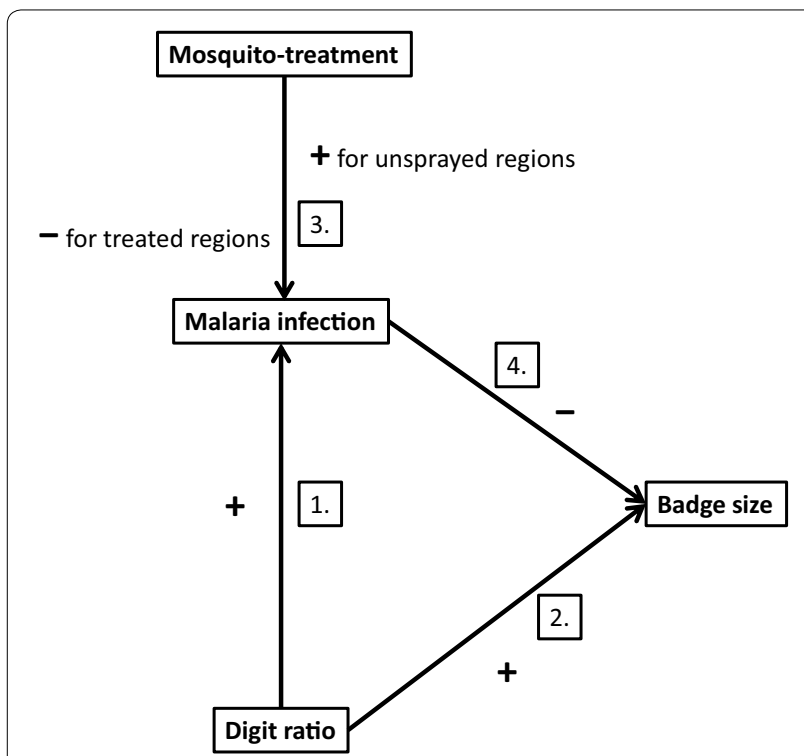

Fig. 1 Model describing the hypotheses investigated in this study. Numbers in the figures correspond to processes hypothesized to take place: 1. High prenatal testosterone exposure, which increases digit ratio has been shown to reduce immunocompetence and hence increases the risk of being infected by malaria, 2 . at the same time birds with higher digit ratios have been shown to have a larger badge size, 3. spraying insecticide reduces vector abundance which in turn has a negative impact on malaria prevalence in a population. The opposite is true in unsprayed, natural areas, and 4. malaria in turn may affect badge size through trade-offs due to the effects of the parasite or by provoking an immune response

\section{Methods Study site}

The Camargue is characterized by a Mediterranean climate with dry and warm summers and mild winters. For this study, two regions, about $20 \mathrm{~km}$ apart, were selected based on habitat similarity but differing in their mosquito control treatment (Fig. 2). The mosquito-controlled region was situated south-east of the protected area Etang de Scamandre and is characterised by a large abundance of rice fields, cattle and horse meadows and water channels. Mosquito control has occurred in this region at regular intervals since the 1970s and although the insecticide campaign targets the vector of human malaria and West-Nile virus, there is some evidence that the two local Culex species, the vectors of Plasmodium in birds, are equally affected by the treatment (Ponçon et al. 2007). The unsprayed region we studied was located east and north of the Etang de Vaccarès and has never experienced mosquito control as it is under regional protection. The land surface cover of the mosquito-treated region is very similar, although agricultural activities are more limited. The landscape in both regions is characterized by large isolated agricultural exploitation units ("mas" and "domaines") many of which sustain substantial sparrow colonies.

In each region four sparrow populations were chosen on basis of similarity of the environment, and of sufficient size of the sparrow colony to allow easy capture. In the controlled region, these sites were: the Centre de découverte Scamandre; Scamandre-Alentours; Domaine de Canavère; and Domaine de de la Fosse. In the natural region we caught sparrows at Tour du Valat; Mas du Pont de Rousty; Armellière; and Romieu. Fieldwork was carried out daily from the 8th of July to 14th of August 2011, a period which encompassed much of the breeding season of the sparrows in the Camargue and in which birds might be particularly susceptible to infections (Sheldon and Verhulst 1996). In total we caught 163 adult males, 78 in the mosquito-treated region and 85 in the natural zone.

\section{Morphological measures and blood sampling}

When adult male house sparrows were captured we immediately took a small blood sample $(<50 \mu \mathrm{l})$ via the brachial vein, and stored it in $90 \%$ ethanol. Following the blood sampling we weighed each bird and measured three aspects of their badge with a digital caliper (to the nearest $0.01 \mathrm{~mm}$ ). These three different measures were picked to account for the dichotomy of visible and total badge size, and were as follows: (1) the maximum length of the badge from the base of the bill to the maximal extent of the black feather on the breast, (Griffith 2000), (2) the directly visible width of the badge allowing us to calculate visible badge size (VBS) and (3) the total width of the badge (also defined by feathers with a dark base but clear tips at the edge of the badge; Møller and Erritzøe 1992) for calculating total badge size (TBS). We used the formula given by (Møller 1987) to calculate the actual size of the badge. We measured the digit ratio following the method of (Navarro et al. 2007): the extended right foot of the bird was gently pressed against a piece of cardboard and both ends of the toe were marked with holes punched into the cardboard with a teasing needle. The distance between the holes was then recorded with a digital caliper.

\section{PCR parasite screening}

In the laboratory we thoroughly dried a small fragment of the ethanol preserved blood before extracting the DNA using DNeasy blood and tissue kits (Qiagen). We encountered some problems with clotted and dried blood failing to lyse properly in the initial step of DNA extraction, so each dried blood pellet was homogenized for 30 s in $200 \mu \mathrm{l}$ of PBS using a Tissuelyser (Qiagen) prior to extraction. The DNA was then extracted according to the manufacturer's guidelines. For each extracted DNA sample 


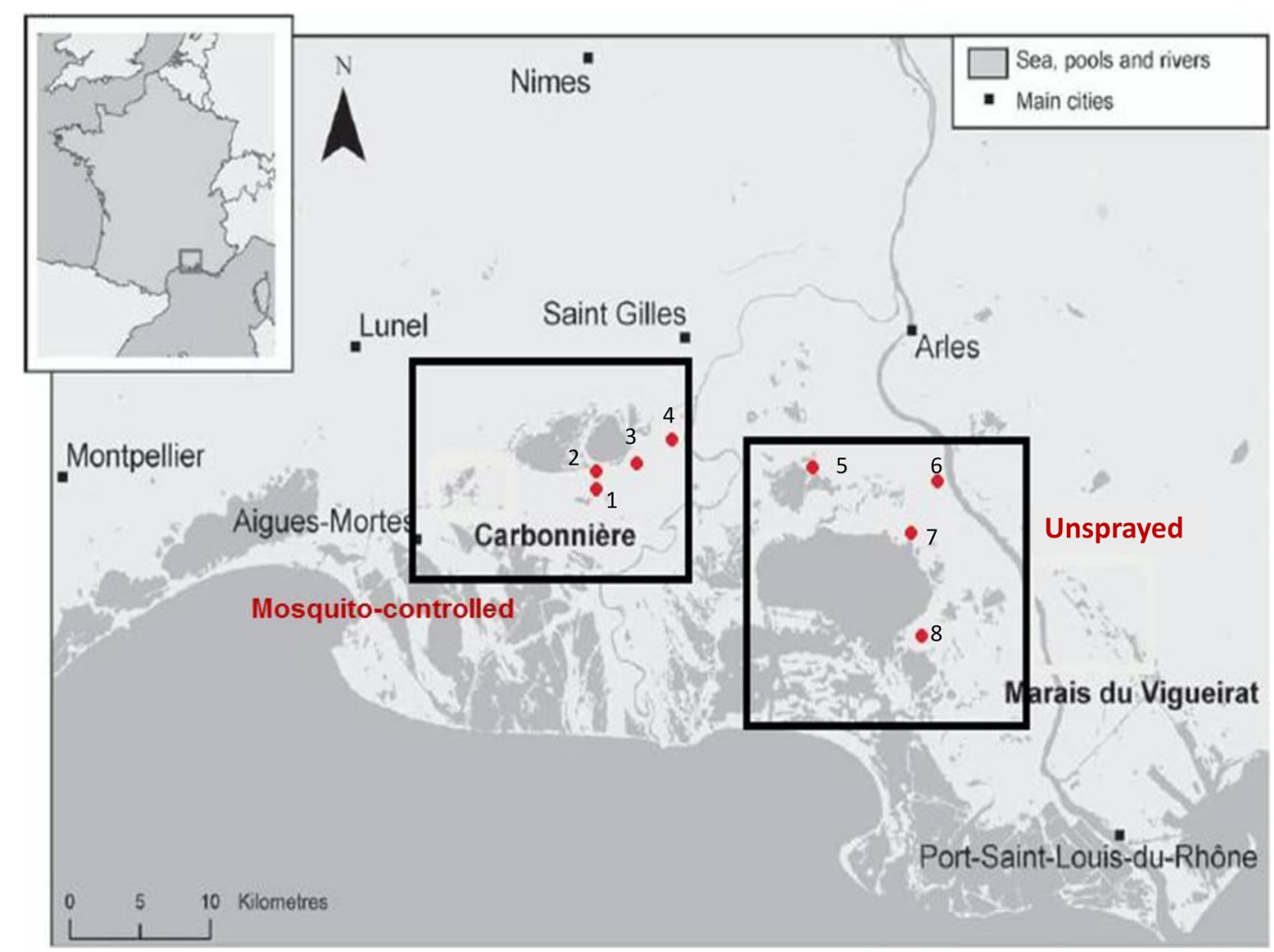

Fig. 2 Map of the study area. The left square is roughly encompassing the mosquito-controlled and the right square is highlighting the natural, uncontrolled zone. The numbered dots within each square are the location of the different sparrow colonies in this study: 1 Scamandre-Alentours, 2 Centre de découverte du Scamandre, 3 Domaine de Canavère, 4 Domaine de la Fosse, 5 Mas du Pont de Rousty, 6 Château Amellière, 7 Romieu, 8 Tour du Valat (map adapted from Ponçon et al. 2007)

we used a nested PCR approach developed by (Waldenström et al. 2004) to identify Plasmodium/Haemoproteus infections. We did not test for Leucocytozoon infection as previously we found no evidence of Leucocytozoon in Camargue sparrows (unpublished data). Both reactions were performed in $25 \mu \mathrm{l}$ volumes. The first reaction contained $2 \mu \mathrm{l}$ of genomic DNA, $0.2 \mu \mathrm{M}$ of each primer (HaemNF [5'-CATATATTAAGAGAATTATGGAG-3'] and HaemNR2 [5'-AGAGGTGTAGCATATCTATCTA C-3']) and $12.5 \mu \mathrm{l}$ MangoMix (Bioline) PCR mastermix. The second reaction contained $1 \mu \mathrm{l}$ of product from reaction 1 with $0.2 \mu \mathrm{M}$ of each primer (HaemF [5'-ATG GTGCTTTCGATATATGCATG-3'] and HaemR2 [5'GCATTATCTGGATGTGATAATGGT-3']) and $12.5 \mu \mathrm{l}$ MangoMix PCR mastermix (Bioline). All PCR runs contained several known positive controls (from blue tits) and negative controls (water). Infections were identified by the presence or absence of bands following the PCR. In order to check that absence of bands was definitely a lack of infection, we used another PCR with universal primers to test that the avian DNA in each sample successfully amplified and any negative samples for malaria infection were repeated to confirm the diagnosis. All positive samples were sent for sequencing (LGC Genomics, Berlin, Germany), and sequences were then edited using Genious (v5.5.6, Biomatters Ltd). All edited sequences were compared to known avian malaria sequences in GENbank and the MalAVi database. We also examined all of the sequences for signs of double peaks associated with mixed infections (Wood et al. 2007).

\section{Statistical analysis}

All statistical analysis was performed in R v.2.15.1. and in SAS (9.1.3 SAS Institute, Cary, USA). Sample size differs for the different tests performed due to missing values. Differences in infection status between treatment regions and sites were tested using a generalised linear model (GLM) defining a binomial error structure. Badge size and digit ratio between infected and uninfected birds was compared with a two-sample $t$ test. We assessed the relationship between digit ratio and badge size using linear regression. Differences in badge size between sites were compared using analysis of variance. Because we found significant differences in badge sizes between sites, we 
included capture site as a random effect in models where badge size was the dependent variable. To do so, we used generalised linear mixed models (GLMMs) with the lme function of the lme4 package in $\mathrm{R}$ v.2.15.1. The most complex model included digit ratio, infection status and bird condition (tarsus and weight) and their interaction as fixed effects and capture site as a random effect. We then performed sequential model simplification, dropping the least significant term until the minimal suitable model was reached (Crawley 2007).

\section{Results}

\section{Malaria prevalence}

Contrary to our expectations, there was no significant difference in the prevalence of infections between regions or sites experiencing different insecticide treatments (treatment regions: $z=0.449, p=0.653$; sites: $z \min =$ $0.131, z \max =1.072, p$ values $\min =0.28, \max =0.89$ ). Prevalence was high in both regions, with $78.4 \%$ of birds infected in the sprayed zone and $81.3 \%$ infected in the unsprayed zone, and within-site prevalence ranged from 70 to $90 \%$ in both zones. The most prevalent strain at each site was Plasmodium relictum SGS1 (82.3 \% of all infections), followed by Plasmodium relictum GRW11 (5.8\% of all infections), PADOM5 (0.025\%), COLL1 $(0.017 \%)$ and P5 (0.0084\%). The absence of a difference in prevalence between regions is an indication that large-scale mosquito control has no significant effect on malaria occurrence in sparrow populations. For the purposes of this study we assume that pathogen-imposed selection pressures in both habitat types are very similar, contrary to our initial prediction.

\section{Badge size}

The range of badge sizes observed in males was substantial $\left(276.2-980.2 \mathrm{~cm}^{2}\right)$ for both visible and total badge size. With a repeatability of 0.936 , badge measures were highly repeatable $(F=30.45, p<0.001, n=163)$. Different sites comprised males that differed significantly in badge size, highlighting the importance of local effects due to genetic or environmental differences (VBS: $F=3.485, p=0.0172, n=158$, TBS: $F=3.391$, $p=0.00217, n=158)$. However that difference was not directly due to the infection status of birds because infected and non-infected birds did not differ in badge size even when the site of capture was controlled for as a random effect (VBS: $t=0.57, p=0.56, n=147$, TBS: $t=0.21, p=0.83, n=147$, Fig. 3). Since the infections were so strongly composed of one parasite strain we could not test for differences in badge size mediated by different strains. To test whether differences in badge size between infected and non-infected birds are conditiondependent, we constructed a GLMM including weight, tarsus length, digit ratio and infection status as well as all their interaction as fixed effects and capture site as a random effect. After sequential simplification we found that visible badge size varied with the interaction between infection status and tarsus $(t=2.10, p=0.0379$, $n=124)$ and the interaction between digit ratio and weight $(t=2.12, p=0.0364)$. Total badge size changed solely by the interaction between infection status and tarsus $(t=2.34, p=0.0206, n=145)$. Interaction plots revealed that visible and total badge size declined with tarsus but less so if birds were infected. Visible badge size also changed with weight depending on the size of
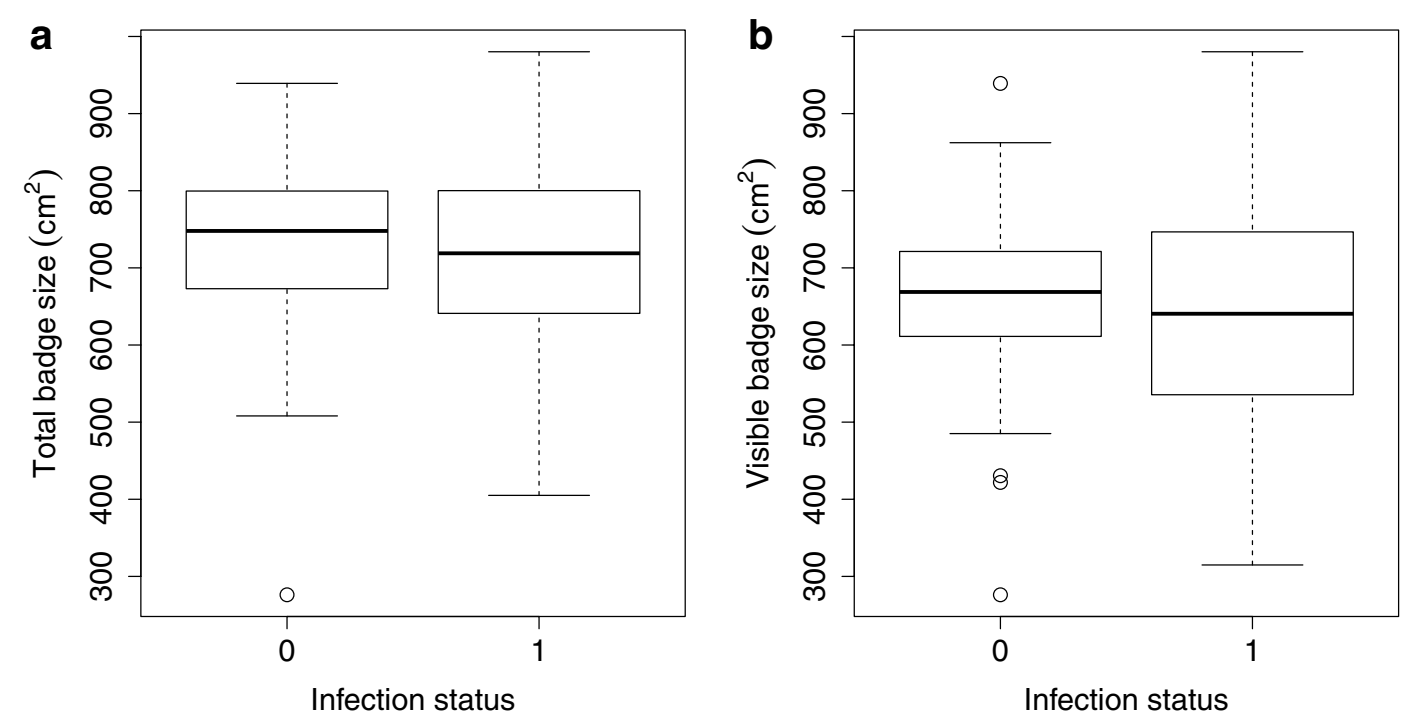

Fig. 3 Variation of total badge size (a) and visible badge size (b) with infection status ( 1 means infected, 0 means uninfected). Horizontal line represents median, top of box 75th percentile, bottom of box 25th percentile, whiskers 1.5 times interquartile range, dots outliers 
digit ratio (Fig. 4). In contrast to findings by others, we could not find any direct correlation between digit ratio and badge size, even when sites were controlled for as a random effect (VBS: $t=0.545003, p=0.5867, n=140$; TBS $: t=0.599513, \quad p=0.5499, \quad n=140) \quad($ Fig. 5$)$. Infected and non-infected birds also had a similar digit ratio, suggesting that maternal testosterone deposition may not affect malaria susceptibility by reduced immunocompetence $(t=0.38, p=0.702, n=131$, digit ratio measures were square-root-transformed). Including sites as a random effect did not change the relationship.

\section{Discussion}

In this study we tested if a secondary sexual signal of male house sparrows (badge size) is connected to avian malaria infections and to a trait related to maternal testosterone deposition (digit ratio). Although there were significant differences in badge size between sites,
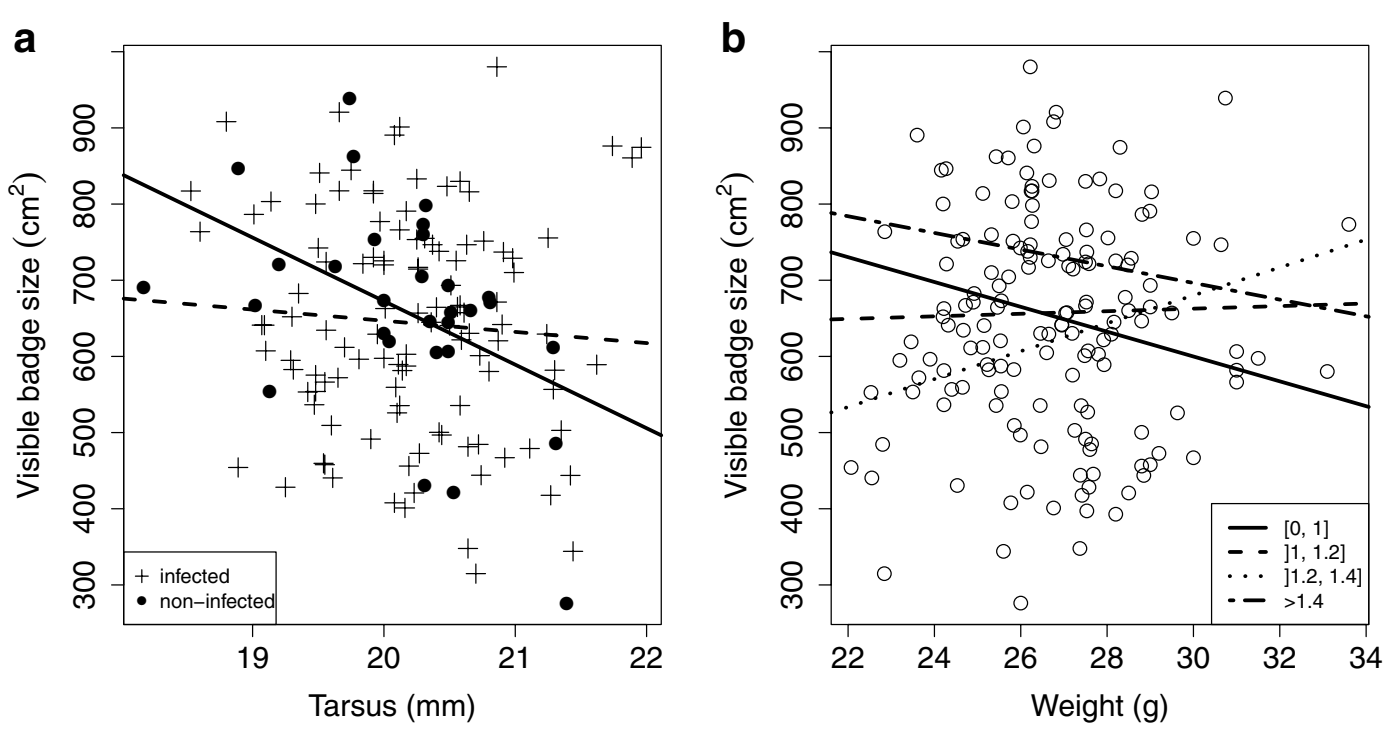

Fig. 4 a Interaction plot of visible badge size against infection status and tarsus, infected birds being marked with a cross and dashed line, uninfected ones with solid dot and solid line, b plot illustrating the interaction between digit ratio and weight on visible badge size with different sizes of digit ratio marked with different lines (see legend)
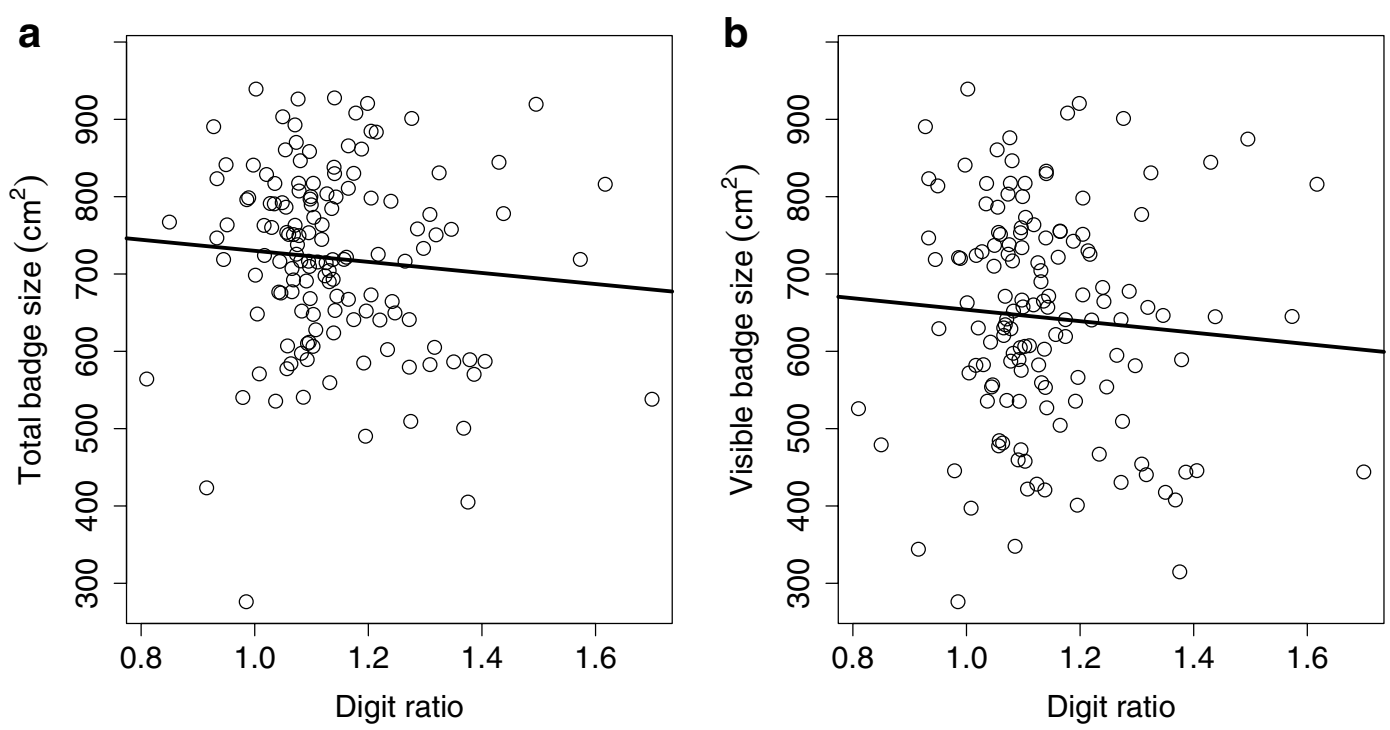

Fig. 5 Variation of total badge size (a) and visible badge size (b) with digit ratio. The lines represent the lines of best fit, assuming a linear correlation 
infected and non-infected birds had no significant difference in badge size and digit ratio. Furthermore there was no direct relationship between digit ratio and badge size, which stands in contrast to other studies that looked at the same traits. Our results offer rather a more complex picture where both visible and total badge size correlate with the interaction between infection status and condition of the bird (tarsus and/or weight) and where the latter may also interact with digit ratio. This observation supports results by Laucht and Dale (2012) who find that badge size is dependent on tarsus and weight but we add the additional insight that those two variables may also interact with malaria infections and maternal testosterone deposition. We also found that the interaction between digit ratio and weight correlates with visible badge size. Visible badge size is achieved by wearing-off of the white feather tips located at the edge of the badge, which is a function of bird activity (Anderson 2006). The maternal testosterone environment has been reported to have an effect on bird aggression (Partecke and Schwabl 2008) and weight may be correlated with fighting ability (Liker and Barta 2001), all-in-all having an effect on the abrasion of feathers.

In contrast to our expectation that reduced vector abundance in mosquito-controlled regions would lead to a lower prevalence of malaria, we found no differences in malaria prevalence between any sites. The high prevalence of Plasmodium in both treatment zones is very similar to that reported from two other studies in this area (Loiseau et al. 2011; Bichet et al. 2014) and seems to be among the highest prevalences observed for house sparrows, at least across France (Bichet et al. 2014). The fact that large-scale vector treatment has no effect on the prevalence of a vector-transmitted disease in this wild population may have several explanations. First, based on previous evidence in the Camargue (Ponçon et al. 2007), we assumed that insecticide spraying predominantly directed against Aedes caspius has an equal effect on Culex mosquitoes. However, we did not directly assess the abundance of different vector species in this study to confirm the effects of insecticide treatments on different mosquito species at each study site and insecticide resistance is known to occur in Culex pipiens near our study area (Lenormand et al. 1999; Labbé et al. 2005). Assessment of location-specific abundance of mosquitoes in relation to mosquito-control programmes is an ongoing project for our research group. Secondly, even assuming that there was a difference in Culex abundance between sites, it is possible that there is an asymptotic relationship between malaria prevalence and vector abundance. In this case, despite reduced numbers of vectors prevalence of disease in the host population would remain unaffected, a possibility already recognized by Ross (1910).
Addressing the links between malaria prevalence and mosquito abundance at the sites we used in this study remains a topic for further investigation. Finally, other variables associated with the vector-controlled zone, most notably the insecticide itself or agriculture-associated pollutants that region which also sustains higher agricultural use, could weaken the sparrows' immune system and increase malaria susceptibility, as previously shown by Bichet et al. (2013), though that effect was most evident in sparrows of highly urbanised areas.

The findings of our work must be seen in the light of the complexity revealed by previous work on sparrow badge size development and avian malaria. First, there is a clear possibility for a temporal mismatch between badge development and timing of infection. Badge development probably depends on the condition of the bird at moult (Moreno-Rueda 2010) whereas infection may have occurred at any time until two weeks before the bird was caught (the limit of detection of malaria blood stages is generally two weeks post-infection; Valkiunas 2004). Some evidence suggests that wild birds are able to clear malaria infections (Knowles et al. 2011), so if there really is a trade-off between badge size and malaria infection, it would be valuable to investigate the infection status at moult (i.e. in the late summer/autumn) and assess badge size the following year. However, data from other birds in the same population suggests that the males in this study were probably carrying chronic infections which they were likely to have maintained for a long time (Larcombe, unpublished data). This temporal mismatch can also occur over longer periods: a "snapshot" where a correlation is established between badge size and other factors at a distinct point in time inevitably ignores some crucial information. This picture is complicated by the fact that badge size can change substantially from one breeding season to another according to factors like paternal investment (Griffith et al. 1999) and diet (Veiga and Puerta 1996) or due to factors that influence the whole cohort like population size and weather (Jensen et al. 2006). It is imaginable that males that experience multiple malaria infections during their lifetime would trade-off badge size development in time rather than through direct physiological trade-offs. The exact age of the birds in this study was not known, although age has been shown to correlate with badge size (Nakagawa et al. 2007; Roberts et al. 2012) and susceptibility to infection (Mackinnon and Marsh 2010; Bichet et al. 2014). Measuring both badge size and infection status over the course of a life-time may account for these differences, however, in wild populations this is technically extremely difficult to accomplish.

Badge size has been shown to be sensitive to many environmental effects, as suggested in this study by the significant differences in badge size between capture 
sites. Jensen et al. (2006) showed the existence of strong cohort effects on badge size, determined by weather and density-dependence during the early development. The sparrow populations in this study may have differed in e.g. food availability, population size or age structure, which could influence the observed inter-site differences. As badge size has a hereditary component and as there is only little dispersal between sparrow colonies (Griffith et al. 1999; Anderson 2006), genetic drift may play some role in badge size, though Loiseau et al. (2009) reckon that genetic differences at such small scales should be unimportant. There are many other potentially important variables we did not investigate in our study, for example current plasma testosterone levels in the blood (Gonzalez et al. 2001; Buchanan et al. 2010; Laucht et al. 2011), nutritional status (Veiga and Puerta 1996) and social environment (Laucht and Dale 2012), all of which could interact with infection status to affect badge size. Furthermore, an avian malaria infection is not just characterised by the presence of the parasite in the blood: males with higher levels of parasitemia may face bigger tradeoffs, a fact we could not control for by using absence/ presence data for infections. However, since parasitemia is not constant during the course of an infection but is characterised by an initial acute phase before dropping to low levels with occasional relapses, it remains unclear how informative single measures in time of parasitemia taken from adult birds would be Cornet et al. (2014). Coinfections by other parasites may also play an important role: if badge size represents an integrative signal of the overall long-term parasite burden of an individual, as has been shown for bill colour in blackbirds (Biard et al. 2010), malaria status on its own may be insufficient in influencing badge size significantly. Finally, there is a clear possibility that the chronic nature of many malarial infections don't pose enough of a challenge to the bird for that trade-off to be visible in sexual signals, especially since there is some evidence that avian malaria prevalence is not directly associated with the elaboration of sexual signals in birds (Garamszegi and Møller 2012).

Egg-testosterone deposition, measured by the digit ratio, has been reported to correlate with numerous advantages like increased growth rate, accelerated embryonic development and higher social rank (Mazuc et al. 2003). A potential cost of testosterone deposition may be decreased immunocompetence (Navarro et al. 2007; Sandell et al. 2009). We found no evidence for this in this study, as there was no difference in digit ratio between infected and non-infected birds. Explanations similar to those provided above for badge size may also account for the lack of effect of digit ratio on infection. However, badge size did not correlate directly with digit ratio in this study, which contradicts the results of Navarro et al. (2007) who found a positive correlation between visible badge size and digit ratio. The absence of a direct correlation in this study with a larger sample of males than (Navarro et al. 2007) shows that a positive relationship between digit ratio and badge size is far from universal and may be season or population-specific and more importantly, that digit ratio may interact with bird weight as found in this study. Seasonal effects may be especially relevant for visible badge size, the size of which increases with increasing time from moult (Anderson 2006). This study highlights one of the problems in finding evidence for the hypotheses explaining maintenance of sexual signals: though trade-offs between disease and sexual signals are probably present, they may be very hard to observe due to the many confounding variables and varying timescales at which they operate. This study makes this case for avian malaria in house sparrows. We showed that infection status and maternal effects may have a condition-dependent effect on the house sparrow badge.

\section{Authors' contributions}

PLGB did most of the fieldwork but with considerable support from SDL, who also performed most of the labwork. Both authors read and approved the final manuscript.

\section{Author details \\ ${ }^{1}$ St Peter's College, University of Oxford, New Inn Hall Street, Oxford OX1 2DL, UK. ${ }^{2}$ Present Address: Institute of Evolutionary Biology, University of Edin- burgh, Charlotte Auerbach Road, Edinburgh EH9 3FL, UK. ${ }^{3}$ Edward Grey Insti- tute of Field Ornithology, University of Oxford, South Parks Road, Oxford OX1 3PS, UK. ${ }^{4}$ Centre de Recherche de la Tour du Valat, Le Sambuc, 13200 Arles, France. ${ }^{5}$ Jesus College, University of Oxford, Turl Street, Oxford OX1 3DW, UK. ${ }^{6}$ Present Address: Institute of Biodiversity Animal Health and Comparative Medicine, University of Glasgow, Graham Kerr Building, Glasgow G12 8QQ, UK.}

\section{Acknowledgements}

First of all we would like to thank all the people and organisations that gave us permission to gather data, especially Jérémiah Petit at La réserve naturelle regionale du Scamandre, the Conservatoire du Littoral, Gaël Hemery at the Parc naturel régional de Camargue, Patrick Grillas and the Roche family. We are indebted to many colleagues and friends from the Tour du Valat research station (TdV), and from the Edward Grey Institute (EGI) for their useful advice and ideas. Special thanks go to Michel Gauthier-Clerc, Ben Sheldon, Marion Vittecoq and Arnaud Bechet who gave significant advice on the realisation of this project as well as feedback on the results. Finally, we would also like to thank the TdV for providing PLGB with accommodation as well as creating the friendly work environment that rendered this research project a delight. All fieldwork was carried out under a licence approved by the French Bird Ringing Authority C.R.B.P.O. This study was jointly funded by the TdV, the EGl and Jesus College, Oxford. We would finally like to thank an anonymous reviewer for very pertinent comments that significantly improved the manuscript.

\section{Competing interests}

Both authors declare that they have no competing interests.

Received: 2 May 2015 Accepted: 6 October 2015

Published online: 23 November 2015 


\section{References}

Anderson TR. Biology of the ubiquitous house sparrow: from genes to populations. New York: Oxford University Press; 2006.

Andersson MB. Sexual selection. Princeton: Princeton University Press; 1994

Badyaev AV, Uller T. Parental effects in ecology and evolution: mechanisms, processes and implications. Philos Trans R Soc B. 2009;364(1520):1169-77.

Biard C, Saulnier N, Gaillard M, Moreau J. Carotenoid-based bill colour is an integrative signal of multiple parasite infection in blackbird. Naturwissenschaften. 2010;97(11):987-95.

Bichet C, Scheifler R, Coeurdassier M, Julliard R, Sorci G, Loiseau C. Urbanization, trace metal pollution, and malaria prevalence in the house sparrow. PLoS One. 2013;8(1):53866.

Bichet C, Sorci G, Robert A, Julliard R, Lendvai AZ, Chastel O, Garnier S, Loiseau C. Epidemiology of Plasmodium relictum infection in the house sparrow. J Parasitol. 2014;100(1):59-65.

Bonneaud C, Pérez-Tris J, Federici P, Chastel O, Sorci G. Major histocompatibility alleles associated with local resistance to malaria in a passerine. Evolution. 2006;60(2):383-9.

Buchanan K, Evans M, Goldsmith A. Testosterone, dominance signalling and immunosuppression in the house sparrow, Passer domesticus. Behav Ecol Sociobiol. 2003;55(1):50-9.

Buchanan K, Evans M, Roberts M, Rowe L, Goldsmith A. Does testosterone determine dominance in the house sparrow, Passer domesticus? an experimental test. J Avian Biol. 2010:41(4):445-51.

Burley NT, Foster VS. Digit ratio varies with sex, egg order and strength of mate preference in zebra finches. Proc R Soc Lond Ser B. 2004:271(1536):239-44

Cain KE, Burns CMB, Ketterson ED. Testosterone production, sexually dimorphic morphology, and digit ratio in the dark-eyed junco. Behav Ecol. 2013;24(2):462-9.

Cornet S, Nicot A, Rivero A, Gandon S. Evolution of plastic transmission strategies in avian malaria. PLoS Pathog. 2014;10(9):1004308.

Cornwallis CK, Uller T. Towards an evolutionary ecology of sexual traits. Trends Ecol Evol. 2010;25(3):145-52.

Crawley MJ. The R Book. Chichester: Wiley; 2007.

Danchin É, Charmantier A, Champagne FA, Mesoudi A, Pujol B, Blanchet S. Beyond DNA: integrating inclusive inheritance into an extended theory of evolution. Nat Rev Genet. 2011;12(7):475-86.

Dolnik OV, Hoi H. Honest signalling, dominance hierarchies and body condition in house sparrows Passer domesticus (Aves: Passeriformes) during acute coccidiosis. Biol J Linn Soc. 2010;99(4):718-26.

Duffy DL, Bentley GE, Drazen DL, Ball GF. Effects of testosterone on cell-mediated and humoral immunity in non-breeding adult European Starlings. Behav Ecol. 2000;11(6):654-62.

Folstad I, Karter AJ. Parasites, bright males, and the immunocompetence handicap. Am Nat. 1992;139(3):603-22.

Galván I, Alonso-Alvarez C. Yolk testosterone shapes the expression of a melanin-based signal in great tits: an antioxidant-mediated mechanism? J Exp Biol. 2010;213(18):3127-30.

Garamszegi LZ, Møller AP. The interspecific relationship between prevalence of blood parasites and sexual traits in birds when considering recent methodological advancements. Behav Ecol Sociobiol. 2012;66(1):107-19.

Gonzalez G, Sorci G, Smith LC, Lope F. Testosterone and sexual signalling in male house sparrows (Passer domesticus). Behav Ecol Sociobiol. 2001;50(6):557-62.

Griffith SC. A trade-off between reproduction and a condition-dependent sexually selected ornament in the house sparrow Passer domesticus. Proc R Soc Lond B. 2000;267(1448):1115-9.

Griffith SC, Owens IP, Burke T. Environmental determination of a sexually selected trait. Nature. 1999:400(6742):358-60.

Groothuis TG, Eising CM, Dijkstra C, Müller W. Balancing between costs and benefits of maternal hormone deposition in avian eggs. Biol Lett. 2005;1(1):78-81.

Hamilton WD, Zuk M. Heritable true fitness and bright birds: a role for parasites? Science. 1982;218(4570):384-7.

Jensen H, Svorkmo-Lundberg T, Harald Ringsby T, Sæther BE. Environmental influence and cohort effects in a sexual ornament in the house sparrow, Passer domesticus. Oikos. 2006;114(2):212-24.

Knowles SC, Wood MJ, Alves R, Wilkin TA, Bensch S, Sheldon BC. Molecula epidemiology of malaria prevalence and parasitaemia in a wild bird population. Mol Ecol. 2011;20(5):1062-76.
Labbé $\mathrm{P}$, Lenormand T, Raymond M. On the worldwide spread of an insecticide resistance gene: a role for local selection. J Evol Biol. 2005;18(6):1471-84.

Laucht S, Dale J. Development of badges of status in captive male house sparrows (Passer domesticus) in relation to the relative ornamentation of flock-mates. Ethology. 2012;118(7):644-53.

Laucht S, Dale J, Mutzel A, Kempenaers B. Individual variation in plasma testosterone levels and its relation to badge size in house sparrows, Passer domesticus: It's a night-and-day difference. Gen Comp Endocrinol. 2011:170(3):501-8.

Lenormand T, Bourguet D, Guillemaud T, Raymond M. Tracking the evolution of insecticide resistance in the mosquito Culex pipiens. Nature. 1999;400(6747):861-4

Liker A, Barta Z. Male badge size predicts dominance against females in house sparrows. Condor. 2001;103(1):151.

Loiseau C, Richard M, Garnier S, Chastel O, Julliard R, Zoorob R, Sorci G. Diversifying selection on mhc class $i$ in the house sparrow (Passer domesticus) Mol Ecol. 2009;18(7):1331-40.

Loiseau C, Zoorob R, Robert A, Chastel O, Julliard R, Sorci G. Plasmodium relic tum infection and mhc diversity in the house sparrow (Passer domesticus). Proc R Soc B. 2011:278(1709):1264-72.

Mackinnon M, Marsh K. The selection landscape of malaria parasites. Science. 2010:328(5980):866-71.

Manning JT. Digit ratio: a pointer to fertility, behavior, and health. New Jersey: Rutgers University Press; 2002.

Marzal A, Ricklefs RE, Valkiunas G, AlbayrakT, Arriero E, Bonneaud C, Czirjak GA, Ewen J, Hellgren O, Dita H, et al. Diversity, loss, and gain of malaria parasites in a globally invasive bird. PLoS One. 2011;6(7):21905.

Mazuc J, Bonneaud C, Chastel O, Sorci G. Social environment affects female and egg testosterone levels in the house sparrow (Passer domesticus). Ecol Lett. 2003;6(12):1084-90.

Moreno-Rueda G. Experimental test of a trade-off between moult and immune response in house sparrows Passer domesticus. J Evol Biol. 2010:23(10):2229-37.

Møller AP. Social control of deception among status signalling house sparrows. Passer domesticus. Behav Ecol Sociobiol. 1987;20(5):307-11.

Møller A, Erritzøe J. Acquisition of breeding coloration depends on badge size in male house sparrows Passer domesticus. Behav Ecol Sociobiol. 1992:31(4):271-7.

Müller W, Lessels CM, Korsten P, von Engelhardt N. Manipulative signals in family conflict? On the function of maternal yolk hormones in birds. Am Nat. 2007;169:84-96.

Nakagawa S, Ockendon N, Gillespie DO, Hatchwell BJ, Burke T. Assessing the function of house sparrows' bib size using a flexible meta-analysis method. Behav Ecol. 2007:18(5):831-40.

Navarro C, De Lope F, Marzal A, Møller A. Predation risk, host immune response, and parasitism. Behav Ecol. 2004;15(4):629-35.

Navarro C, de Lope F, Møller AP. Digit ratios (2d: 4d), secondary sexual characters and cell-mediated immunity in house sparrows. Passer domesticus. Behav Ecol Sociobiol. 2007:61(8):1161-8.

Partecke J, Schwabl H. Organizational effects of maternal testosterone on reproductive behavior of adult house sparrows. Dev Neurobiol. 2008;68(14):1538-48.

Poiani A, Goldsmith A, Evans M. Ectoparasites of house sparrows (Passer domesticus): an experimental test of the immunocompetence handicap hypothesis and a new model. Behav Ecol Sociobiol. 2000:47(4):230-42.

Ponçon N, Toty C, L'ambert G, Le Goff G, Brengues C, Schaffner F, Fontenille D. Population dynamics of pest mosquitoes and potential malaria and West Nile virus vectors in relation to climatic factors and human activities in the Camargue, France. Med Vet Entomol. 2007;21(4):350-7.

Poulin B. Indirect effects of bioinsecticides on the nontarget fauna: the Camargue experiment calls for future research. Acta Oecol. 2012;44:28-32.

Randolph SE, Rogers DJ. The arrival, establishment and spread of exotic diseases: patterns and predictions. Nat Rev Microbiol. 2010;8(5):361-71.

Roberts ML, Buchanan KL, Evans MR. Testing the immunocompetence handicap hypothesis: a review of the evidence. Anim Behav. 2004;68(2):227-39.

Roberts ML, Buchanan KL, Goldsmith AR, Evans MR. The role of testosterone in bib size determination in the male house sparrow Passer domesticus, is age dependent. J Avian Biol. 2012:43(3):264-72.

Ross R. The prevention of malaria. London: John Murray; 1910.

Saino N, Møller A, Bolzerna A. Testosterone effects on the immune system and parasite infestations in the barn swallow (Hirundo rustica): an 
experimental test of the immunocompetence hypothesis. Behav Ecol. 1995;6(4):397-404.

Sandell MI, Tobler M, Hasselquist D. Yolk androgens and the development of avian immunity: an experiment in jackdaws (Corvus monedula). J Exp Biol. 2009;212(6):815-22.

Schwabl H. Yolk is a source of maternal testosterone for developing birds. Proc Natl Acad Sci. 1993;90(24):11446-50.

Schwabl H. Maternal testosterone in the avian egg enhances postnatal growth. Comp Biochem Physiol Part A. 1996;114(3):271-6.

Sheldon BC, Verhulst S. Ecological immunology: costly parasite defences and trade-offs in evolutionary ecology. Trends Ecol Evol. 1996;11(8):317-21.

Stearns S. The Evolution of Life Histories. Oxford: OUP; 1992.

Tschirren B, Saladin V, Fitze PS, Schwabl H, Richner H. Maternal yolk testosterone does not modulate parasite susceptibility or immune function in great tit nestlings. J Anim Ecol. 2005;74(4):675-82.

Valkiunas G. Avian malaria parasites and other haemosporidia. Boca Raton: CRC Press; 2004
Veiga JP, Puerta M. Nutritional constraints determine the expression of a sexual trait in the house sparrow, Passer domesticus. Proc R Soc Lond Ser B. 1996;263(1367):229-34.

Verhulst S, Dieleman S, Parmentier H. A tradeoff between immunocompetence and sexual ornamentation in domestic fowl. Proc Natl Acad Sci. 1999;96(8):4478-81.

Waldenström J, Bensch S, Hasselquist D, Östman Ö. A new nested polymerase chain reaction method very efficient in detecting Plasmodium and Haemoproteus infections from avian blood. J Parasitol. 2004;90(1):191-4.

Wood MJ, Cosgrove CL, Wilkin TA, Knowles SC, Day KP, Sheldon BC. Withinpopulation variation in prevalence and lineage distribution of avian malaria in blue tits, Cyanistes caeruleus. Mol Ecol. 2007;16(15):3263-73.

Zahavi A. Mate selection-a selection for a handicap. J Theor Biol. 1975;53(1):205-14.

Zuk M. Sex differences in parasite infections: patterns and processes. Int J Parasitol. 1996;26(10):1009-23.

\section{Submit your next manuscript to BioMed Central and take full advantage of:}

- Convenient online submission

- Thorough peer review

- No space constraints or color figure charges

- Immediate publication on acceptance

- Inclusion in PubMed, CAS, Scopus and Google Scholar

- Research which is freely available for redistribution

Submit your manuscript at

www.biomedcentral.com/submit

C Biomed Central 